\title{
The Use of Computerized HRM Systems by Companies in Saudi Arabia
}

\author{
Mashhoor Al-Amri, Adlah A. Alessa, Alharthey Bandar Khalaf \\ Department of Business Administration, Arab East Colleges, Al Hada, Saudi Arabia \\ Email: bkalharthey@arabeast.edu.sa,mnalamri@arabeast.edu,sa-aaalessa@arabeast.edu.sa
}

Received 25 March 2016; accepted 11 April 2016; published 15 April 2016

Copyright (C 2016 by authors and Scientific Research Publishing Inc.

This work is licensed under the Creative Commons Attribution International License (CC BY). http://creativecommons.org/licenses/by/4.0/

(c) () Open Access

\begin{abstract}
This paper investigates the situation of Human Resource systems in the Saudi market by surveying 60 companies. Human Resource and IT managers completed a questionnaire to reflect the current state of Human Resource systems in Saudi Arabia. In the course of the study, eight hypotheses were investigated and proved: HR system users in the companies accounted for less than half of the total staff; most of the companies used Human Resource systems as a part of their automated HR system; several companies used Human Resource management applications developed by their own specialists; the companies' degree of satisfaction with their Human Resource management systems' performance; the readiness of companies to implement new and efficient solutions into their practices; the readiness of companies to adopt an SaaS model; businesses have the potential to make great progress despite obstacles. Results have shown that the Saudi market is ready to adopt and implement such new techniques, but satisfaction levels with current solution are comparatively low and need urgent measures. Progress, especially on the source of an SaaS model, is needed to improve the companies' situation and allow them to take a step towards a more successful future by improving their competitive advantage.
\end{abstract}

\section{Keywords}

HRM Systems, SaaS Model, HR in Saudi, On-Demand Software, Human Capital Management, Talent Management, Human Resource Management Systems

\section{Introduction}

Human Resource systems are the electronic tools which are used to access Human Resource information in order to perform its functions [1]. These systems are continuously being improved and developed worldwide, presenting more opportunities to HR managers. Ultimately, HRM systems evolved from automating personnel accounts to Human Resource management concepts [2], thereby developing to deal with people as an asset rather 
than just as a means of recording staff.

Most developed and fast-growing American companies allocate considerable funds to adopt HRM systems as well as Information Management systems [3], mainly to automate daily work and to create and maintain databases. These systems provide some of the following functions:

1) Payroll. To mechanize the payment method;

2) Work time. To record the employees' work and analyze their efficiency;

3) Benefits administration. To control the workers' participation in benefits and/or remuneration programs;

4) HR management. To cope with all the employees' data besides many other HR data. The system records and analyzes all the data belonging to the employees as well as covering many other HR issues;

5) Recruiting. Electronic/online recruiting is more common than ever;

6) Training. To direct employees' training and continuous development, in addition to some other modules [4].

Although implementation of HR system has been established for some considerable time, their outcomes are still as what the Human Resources managers are looking for. For example, according to a study conducted by [5], thirty percent of enterprises using these systems are unhappy with their outcomes [6].

One main difficulty is that businesses outgrow their software programs, which makes replacing the system more difficult. This fact often makes finding other solutions complicated for companies, especially when workers resist the need for constant training with new applications. This can lead to dissatisfaction from employees, time wasting, reductions in efficiency and, consequently, money wasting.

It is necessary for organizations to have a solid foundation to adapt to a competitive, highly uncertain environment. On the other hand, trying different systems gives the advantage of choosing the best appropriate formatting for the organization [7]. Finding the right system is the way to improve the company's situation. A high quality HR system should have the ability to develop and be modified to meet the organization's growth [8].

Some HR systems offer upgrades for a considerable amount of money, while some offer free upgrades if paying subscription fees [9]. These choices are convenient for companies.

After calculating the benefits of a variety of Human Resource systems' solutions, managers can determine the value or may decide that these systems are not beneficial for them. For example, they might consider HR systems are inappropriate for their business type or for the uniqueness of their products (goods or services). Despite the time-saving aspect, companies might decide to give up such systems [10] if it leads to a reduction in mistake-making and information loss. However, it is primarily a money-saving opportunity by avoiding mistakes, saving information and many other benefits [11].

For this study, the researched group is firms in the Saudi market. Most use HRM systems and practices that are not cutting edge. Many firms still use standard programs from Microsoft Office (MS Word, Excel, and Access) or paper mediums which are not specialized for such usages, and consequently these systems do not add value to the organization's competitive advantages.

Other companies use different softwares such as 1C, SAP, and Boss-Kadrovik. 1C and Boss-Kadrovik are Russian systems made to offer opportunities such as recording the staff's work time, recording salaries, recording any deviation in regard to the regular work schedule (business trips, days off, vacations, etc.), payment performance, personnel records, tax calculation, and many other useful functions. Due to the fact that $1 \mathrm{C}$ is a complex program, it is preferably used by professionals in order to optimize the features; this disadvantage is aligned to its high price, while the Boss-Kadrovik program has poor functionality and fewer opportunities. SAP has more features compared with $1 \mathrm{C}$ and Boss-Kadrovik, but it still has some difficulties in settings and maintenance, and a lot of time is needed to incorporate changes brought about by changes to the legislative system. It is also more expensive.

In summary, the current situation does not add value to a company's competitive advantages; it wastes the company's resources and disperses its efforts. SaaS is an abbreviation for Software as a Service, also referred to as "on-demand software". SaaS is a model where software and all corresponding materials and data are hosted in a central base, often in a cloud computing system, which allows users and/or clients' access, usually by the use of a web browser (Software as a Service, n.d.). Recently, this model has spread widely over many types of business need, such as content management, HR, and CRM.

If we are specifically examining the scope of Human Resource, it should be made clear that on-demand $\mathrm{Hu}-$ man Resource applications, depending on the provider and the application characteristics, can offer users a broad human capital management, or talent management, facility in addition to complete HRM System applica- 
tions.

The advantages of SaaS are as follows (Facts about SaaS HR, n.d.):

- It helps to save time and money [12]. No maintenance is needed and it is cheap to install as payment depends on the usage [13].

- It is suitable and does not have access limits. This is one of the most common reasons leading to demand for this application [14]. Compared to its competitors, SaaS provides the best functionality in this aspect [15].

- SaaS is not difficult to change and/or to regulate [16], which makes it useful for growing companies.

- SaaS is easy to configure to exact requirements [17].

- Upgrades are not expensive. When vendors of software develop or improve the application, clients have to pay the fee defined by the vendor as a new license cost.

Thus, SaaS is an optimal solution for companies to ease the process of routine work that needs automation although it might not be suitable for companies which are looking for special HR automated functions.

This study focuses on the following objectives: to explore the recent situation in Saudi companies concerning the use of Human Resource systems; to explore the satisfaction level with current systems; to identify the number of HRM system users in these companies; to find out if there are any extra resources used by these companies; to discover the readiness of such companies to adopt new and efficient solutions into their practices; to explore whether customers in the Saudi market are prepared to adopt an SaaS model; and finally, to determine the main difficulties facing Human Resource system’s implementation.

\section{Methodology}

\section{Participants and Procedure}

Fifty companies from every industry around Saudi participated in the conducted research. The research participants were more than 100 managers of Human Resources and IT departments. There are eight hypotheses examined in this research as per the results and analysis section.

The research questionnaire consists of a group of general questions and a group for more expert views. Among the companies investigated, the most active were large organizations (75\%). The staff number distribution is shown in Figure 1.

\section{Results and Analyses}

\section{Hypothesis 1: Less than half of the staff in companies use the HR system}

As shown in Figure 2, in spite of the fact that the total number of staff in the organizations investigated was great, the majority of Human Resource management system users (53\%) do not exceed 25 employees. These figures indicate that Human Resource management systems are mostly used by the Human Resource managers and department managers. However, companies need to view HRM systems as an opportunity to be exploited.

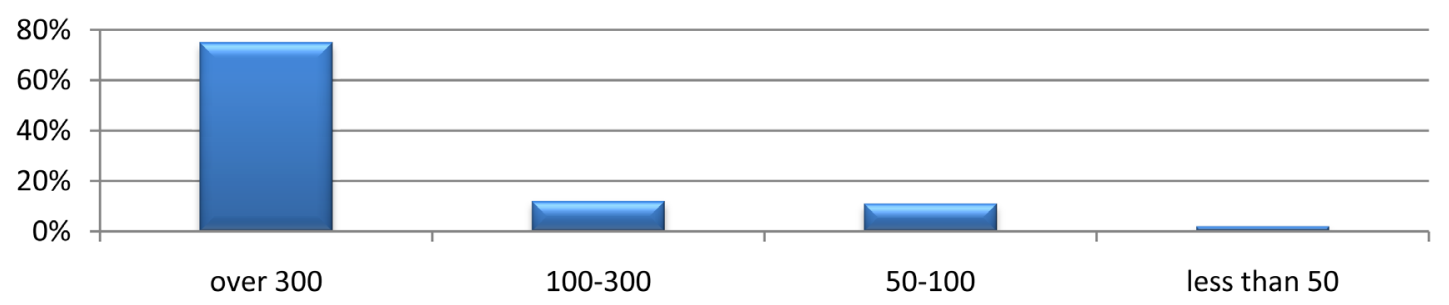

Figure 1. Number of staff in companies that took part in the research.

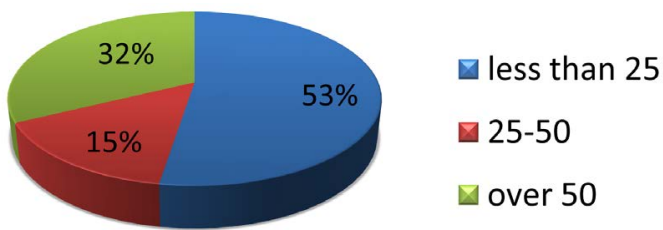

Figure 2. Number of HRM system users. 
Hypothesis 2: Most of the companies use Human Resource systems as a part of their automated HR system

As illustrated in Figure 3, the vast majority of participants (80\%) use resources additional to the installed systems, while $46 \%$ said that they use a combination of several resources in addition to specialized programs such as a paper medium.

As per the data, we observe the following:

1) Many Saudi staff do not use HRM systems properly.

2) Possible reasons for such a situation might be due to the perceived difficulty of Human Resource management system usage; insufficient localization of software, such as incompatibility of applications' functionality with specific Saudi business needs; insufficient functionality; high costs.

3) To improve the current situation, it is essential to arrange campaigns showing the advantages of HRM systems, to build organizations' awareness.

Hypothesis 3: Several companies use Human Resource management applications developed by their own specialists

As shown in Figure 4, a noteworthy number of Human Resource system users choose the 1C system (35\%), while only $31 \%$ have systems developed by their own specialists.

The findings of the research confirm the conclusion drawn from Figure 3: current applications do not fulfill companies' needs, which leads them to create their own solutions using their in-house IT expertise. While this means that there is no fee for any updates or changes using SaaS, it might not be beneficial for companies that need to develop their own systems. To accomplish long-term objectives and to find sufficient solutions, it is important to hire professionals who can cope with the task. Usually, attracting such experts is costly; however, it is obvious that in this case firms have no problem paying extra money in order to have better results. They prefer it to systems which need to be adjusted to suit their special needs or which simply cannot fulfill their needs completely.

Hypothesis 4: The degree of companies' satisfaction with Human Resource management system performance

As per the research, of the respondents which are shown in Figure 5, 40\% are satisfied with their HRM system's current level of performance, while $23 \%$ assessed their HRM system as satisfactory and $17 \%$ assessed it as unsatisfactory.

The exhibited results produce the following conclusions:

1) Although around half of the companies are satisfied with their current systems, this does not mean these systems are efficient. Moreover, if we consider the $30 \%$ of participants who are using their own developments, we realize that the number of those who are satisfied with their off-the-shelf system is even less.

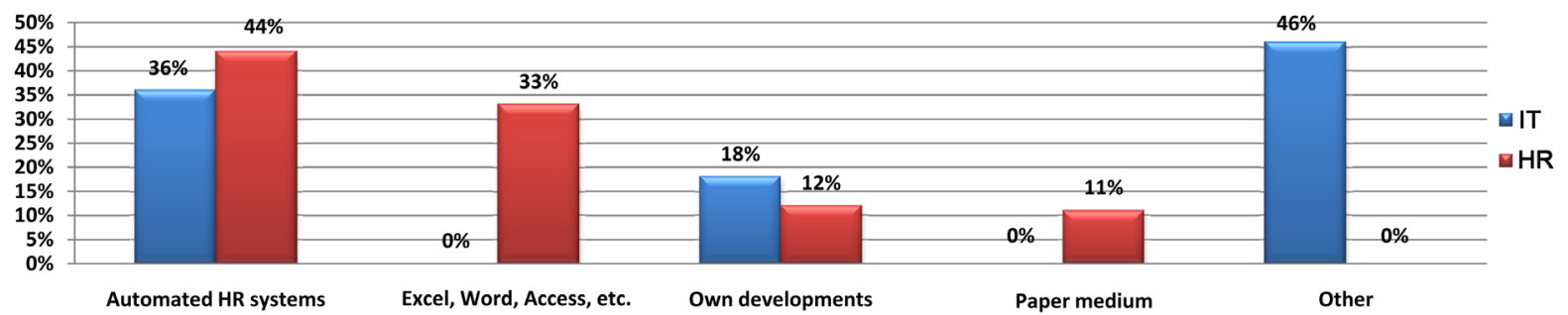

Figure 3. Types of resource and tools used for education, recruiting, and management of human resources.

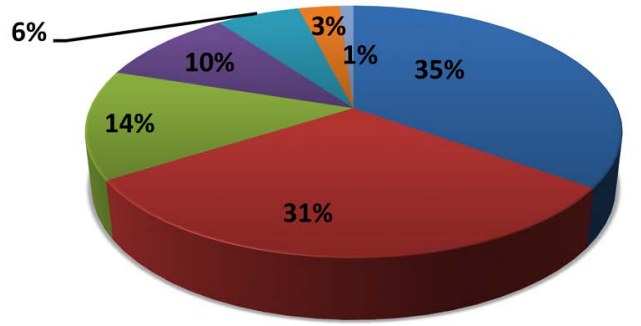

$\square \mathbf{1 C}$

OWn development

$\square$ SAP

$\square$ Hard to answer

$\square$ Boss Kadrovik

Figure 4. Human resource management systems used by Saudi companies. 


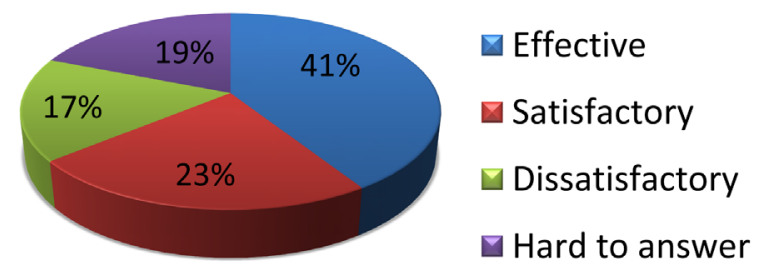

Figure 5. Companies’ satisfaction levels with their Human Resource management system.

2) The results indicate that $60 \%$ assess their HRM systems as inefficient. This agrees with our statement about the need to change the current situation in order to let HR managers work effectively.

3) One-fifth of the participants do not have a definite answer for this question, which indicates that either they do not know the system in use or they do not have experience working on these systems. This result demands an urgent review of the situation.

Hypothesis 5: The readiness of companies to implement new and efficient solutions into their practices As shown in Figure 6, 93\% of the HR experts admitted that there is a need for new HRM systems, which indicates awareness of HR managers in the Saudi market of contemporary trends in Human Resources, besides understanding the need to improve effectiveness.

\section{Hypothesis 6: The readiness of the Saudi market to adopt an SaaS model}

As per the survey and as illustrated in Figure 7, 77\% of participants admitted that neither clients nor vendors were ready for an SaaS model yet. Despite the need to use SaaS's features, companies have not been attracted to it because SaaS is not commonplace in this market. Just 3\% of the participants are ready to adopt an SaaS model.

Hypothesis 7: Companies' readiness to adopt an SaaS model.

Results in Figure 8 show the distribution of responses which can be explained by several issues, such as lack of competencies, previous bad experience with SaaS or other similar applications, or the motivation to invest in their own applications. However, as all respondents have an awareness of the necessity of an HRM system, an appropriate solution can convert this tendency easily and quickly.

Hypothesis 8: Businesses have great progress potential despite obstacles

Until now, we have defined seven primary obstacles to implementing an HR system: inappropriate installed software, the cost, installation and technical difficulty of implementation, low level of managers' interest, variations in the processes of the business, lack of product quality, and employees' resistance. The distribution of respondents' answers is illustrated in Figure 9.

According to the IT managers included in the survey, the main obstacles are lack of interest among the management (22\%), and employees' resistance (18\%). HR managers do not consider managers' lack of interest as a great problem (only $13 \%$ believe it is an obstacle), and employee opposition does not concern them at all (only $2 \%$ are concerned about it). These data reflect the Human Resource managers' confidence in their ability to convince company management about the need and the readiness for such systems. In these two aspects, IT managers misjudged the Human Resource sector's ability to change.

The primary obstacle for $33 \%$ of Human Resource managers is inappropriate software for new systems, while IT managers do not consider it as the main difficulty (only $11 \%$ stated their worry), which indicates that IT readiness for new technologies implementation is underestimated by HR departments. Both sides consider cost as an obstacle at the same level (21\% by IT and $23 \%$ by HR).

\section{Discussion of the Main Results of the HRM Hypotheses}

As per the findings, we observe the following points:

1) The Saudi market is encouraged to adopt HRM systems due to the awareness of IT and HR managers to the opportunities on offer.

2) Meanwhile, the majority of companies are not satisfied with software currently offered, which requires them to design bespoke software in order to save HR data, which is considered as a "half solution".

3) There is a need in the market for similar systems that balance price with quality.

4) It is recommended that such a solution is implemented on an SaaS model. 


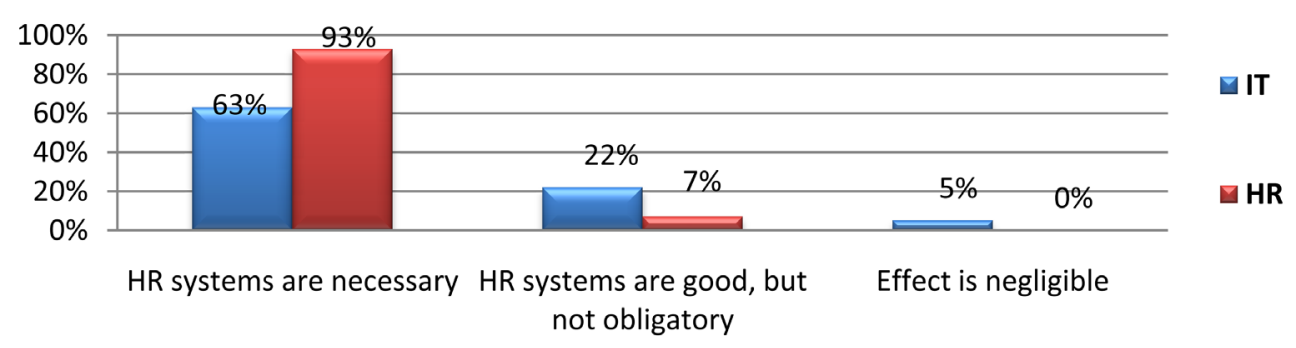

Figure 6. Loyalty levels towards HR systems.
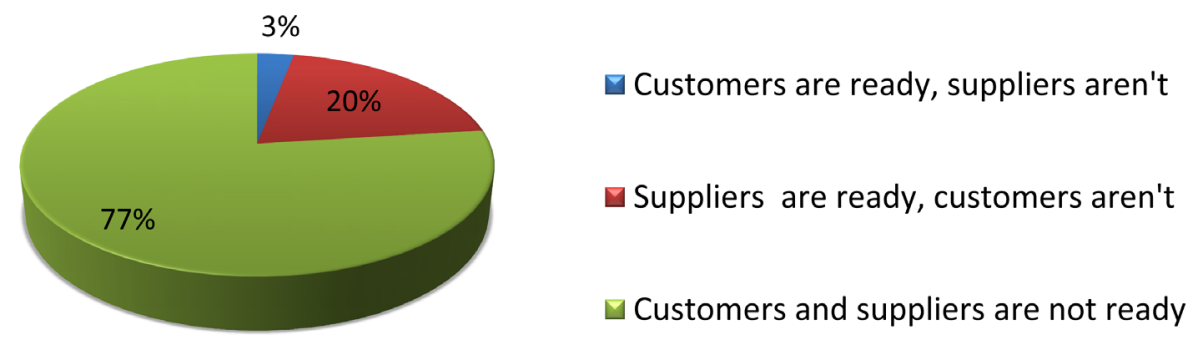

Figure 7. The level of Saudi market readiness to adopt an SaaS model.
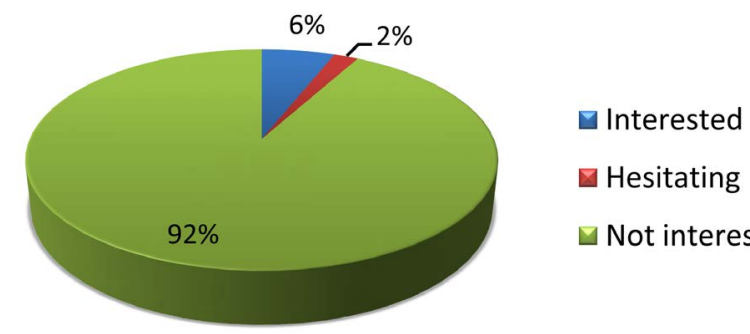

$\square$ Not interested

Figure 8. Companies’ readiness levels to adopt an SaaS model.

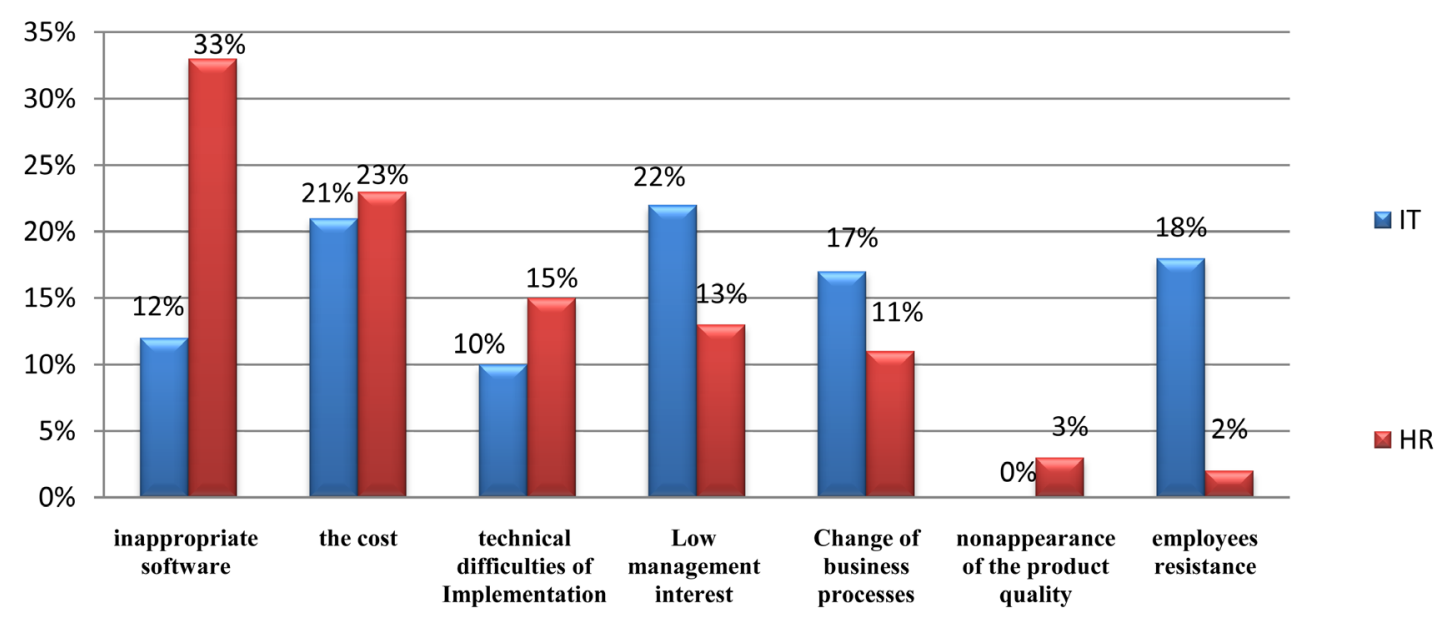

Figure 9. Main obstacles to HR system implementation.

5) Due to the fact that there is no aggressive competition in the Saudi market, it might be easier to adopt such new systems if people are suitably informed about the potential benefits.

\section{References}

[1] Human Resources Systems (n. d.) http://hr.od.nih.gov/hrsystems/default.htm 
[2] Heathfield, S.M. (n. d.) Human Resources Information Systems. http://humanresources.about.com/od/glossaryh/a/hris.htm

[3] Gatewood, R.D., Feild, H. and Barrick, M. (2008) Human Resource Selection. Thomson South-Western, Mason.

[4] Hunter, I., Saunders, J., Boroughs, A. and Constance, S. (2006) HR Business Partners. Gower Publishing Limited, Aldershot, 69-71.

[5] (2010) The Evolution of HR Systems: Update from HR Technology Conference 2010. http://www.bersin.com/blog/post/2010/10/The-Evolution-of-HR-Systems--Update-from-HR-Technology-Conference-2 010.aspx

[6] HR Systems Still Disappointing (2007) http://www.hrmguide.co.uk/systems/survey.htm

[7] Beaman, K., Doran, A., Henson, R., Krebs, V., et al. (2000) 21 Tomorrows: HR Systems in the Emerging Workplace of the 21st Century. Rector Duncan \& Associates, Inc., Austin.

[8] Hendry, C. (1999) Human Resource Management: A Strategic Approach to Employment. The Bath Press, Bath.

[9] Blokdijk, G. (2008) SaaS 100 Success Secrets. E-Book.

[10] Williams, L. (2009) Beware the Pros and Cons of SaaS. http://www.hreonline.com/HRE/story.jsp?storyId=220825812

[11] Chang, W.Y., Abu-Amara, H. and Sanford, J. (2010) Transforming Enterprise Cloud Services. Springer, Berlin.

[12] Velte, A.T., Velte, T.J. and Elsenpeter, R. (2010) Cloud Computing: A Practical Approach. E-Book.

[13] Mather, T., Kumaraswamy, S. and Latif, S. (2009) Cloud Security and Privacy: An Enterprise Perspective on Risks and Compliance. O’Reilly Media, Inc., Sebastopol.

[14] Hatch, R. (2008) SaaS Architecture, Adoption and Monetization of SaaS Projects. The Art of Service Pty Ltd., London.

[15] Bocij, P., Greasley, A. and Hickie, S. (2008) Business Information Systems: Technology, Development and Management. Pearson Education Limited, Essex.

[16] Oshri, I. and Kotlarsky, J. (2010) Global Sourcing of Information Technology and Business Processes. Springer, Berlin.

[17] Moe, J.E. (2010) Why SaaS May Not Be a Good Fit for HR. http://www.comparehris.com/Why-SaaS-May-Not-Be-A-Good-Fit-for-HR/ 